\title{
THE PLACE OF STRATEGIC MARKETING IN THE PREOCCUPATIONS OF THE SMALL AND MEDIUM ENTERPRISES FROM DÂMBOVIṬA COUNTY
}

\author{
Ana-Lucia Ristea ${ }^{l}$ \\ Constanta Popescu ${ }^{2}$ \\ Delia Mioara Popescu ${ }^{3}$
}

\begin{abstract}
In the present stage of the Romanian national economy, in the context of the continual changes caused by globalization and by the market dynamics in the context of the international economic crisis, in order to assure the success and the competitive advantage for one's own business, it is imperative to align one's economic policy to the international standards. The present research aims to approach this topic, which is both necessary and actual, by means of an analysis of the way in which the small and medium enterprises (SMEs), on the one hand, and the great companies, on the other hand, use the opportunities provided by strategic marketing to adapt themselves to the new realities. The question is: Why is it that almost half of the SMEs do not manage to go beyond their first five years of existence? What strategies should they adopt to resist and to develop in an environment where competition is so intense? The object of the present scientific paper is to determine the place occupied by strategic marketing in the preoccupations of the SMEs in Dâmbovița County. In order to attain this goal, we have completed a marketing research whose goal was to determine the position of the place occupied by strategic marketing in the preoccupations of the SMEs from Dâmbovița County.
\end{abstract}

Key words: strategic marketing, competitive advantage, critical success factors

JEL Codes: M31

\section{Introduction}

Today's world, always more interconnected and interdependent, involves more risks for any enterprise. In order to defend itself from the external shocks of turbulence and uncertainty, the enterprise needs to develop a marketing system allowing it to establish its market targets and its strategic position -crucial decisions for attaining and maintaining high quality performances in business (W. D. Cravens and F. N. Piercy, 2009, p. 184). These essential decisions cover the paradigmatic core of the corporate strategic marketing, whose mission is to adopt and to improve the enterprise's commercial strategy, as an approach allowing it to turn to attractive economic opportunities, which provide a potential of growth and profitability.

The main purpose of this paper is to know the actual state of the strategic marketing practice on the level of the SMEs in Romania. The scientific argumentation relies on the analysis of the information gathered by means of a survey carried out among marketing specialists. The survey was filled in by a representative sample of companies from Dâmbovița County, a county faced with real economic problems, from the category of the underprivileged zones of Romania. At the same time, the area covered by our research in the field - Dâmboviţa County - is justified by the authors'

\footnotetext{
${ }^{1}$ Valahia University of Targoviste, Romania

${ }^{2}$ Valahia University of Targoviste, Romania,e-mail: tantapop@yahoo.com

${ }^{3}$ Valahia University of Targoviste, Romania
} 
interest in realizing scientific research studies from the perspective of the collaboration of a part of the academics and doctoral students of the Faculty of Economics from "Valahia" University Târgovişte (the capital city of Dâmbovița County) with the cu firms that absorb on the labor market most of the students that this higher education institution trains on the three levels of professional instruction: bachelor degree (BSc/BA), master degree, doctoral studies.

We highlight the fact that the results of this particular research in the field confirm the conclusions of other researches undertaken by different specialists from other regions and zones from Romania. Such a research is carried out periodically, on a sample of enterprises on a national level, within a scientific contract concluded between the National Authority for the SMEs and the Romanian National Council of the Private SMEs. The results of the research have been published in the White Charter of the SMEs of Romania. One of the significant aspects highlighted by the survey completed in the methodological context of this study is the need to boost the marketing activity, a demand representing a managerial priority in more than half of the SMEs under analysis. So, our research aims to help the Romanian SMEs reinforce their deficient image, their poor integration and their lack of a secure knowledge basis.

\section{Paradigmatic elements for strategic marketing}

In the specialized literature, the definitions given to marketing are very numerous, almost each author being concerned to provide his own landmarks for the content of its role and its functions. Actually, these definitions have evolved in time, naturally reflecting the change of practices and the relative importance of the strategic and epistemological concerns of the moment.

This great diversity of definitions is largely backed by the fact that the term "marketing" covers, as Ph. Kotler highlighted, three dimensions (P. Amerein et all., 2002, p.4):

A scientific dimension, which gives marketing its status of academic discipline, which studies the market relations among economic exchange partners;

A managerial dimension, concentrated in the management of marketing, focused on the projection of an organized analysis-and-action approach;

A philosophical dimension, given by the "state of spirit", based on P. Drucker's idea concerning the need for the corporate efforts to be oriented towards attracting and keeping a client; today, even more emphasis is put on this dimension, considering that the deficit of clients, and not of goods, is one of the major issues that enterprises are faced with (Ph. Kotler, 2004, p.11).

As the epistemological approach of the marketing discipline is not our concern now, next, we are going to focus on the two complementary and interdependent approaches that marketing relies on: the first has to do with the analysis domain ("understanding the market") - strategic marketing, whose mission is to adopt and improve the corporate commercial strategy; the second, which has to do with the action domain ("conquering the markets") is operational marketing, whose goal is to elaborate the marketing mix (J.J. Lambin, 1999, p.7).

Strategic marketing is the approach orienting the enterprise towards the economic opportunities attractive for it (well adapted to its resources and know-how) and offering a potential of growth and profitability. This approach is on an average and long term and its goal is to substantiate the corporate mission, to define its objectives, to elaborate a strategy of developmentand-pursuit of a balanced structure of the product portfolio (J.J. Lambin, 1994, p.8).

The marketing approach is part of the general corporate strategic approach. The elaboration of the marketing strategy begins with the analysis of the corporate needs (through a micro- and macro-segmentation) and the analysis of the corporate attractiveness and competitiveness, continuing with the analysis of the activity portfolio, so that after the choice of a development strategy, it may then be translated into an operational action program.

The marketing specialist is called to make a deep search concerning the corporate opportunities and risks, and concerning the stakes related to the choice of different target-markets. 
The corollary of his mission of contributing to the substantiation of the general corporate strategy is the task to supervise the competitors and the market evolution.

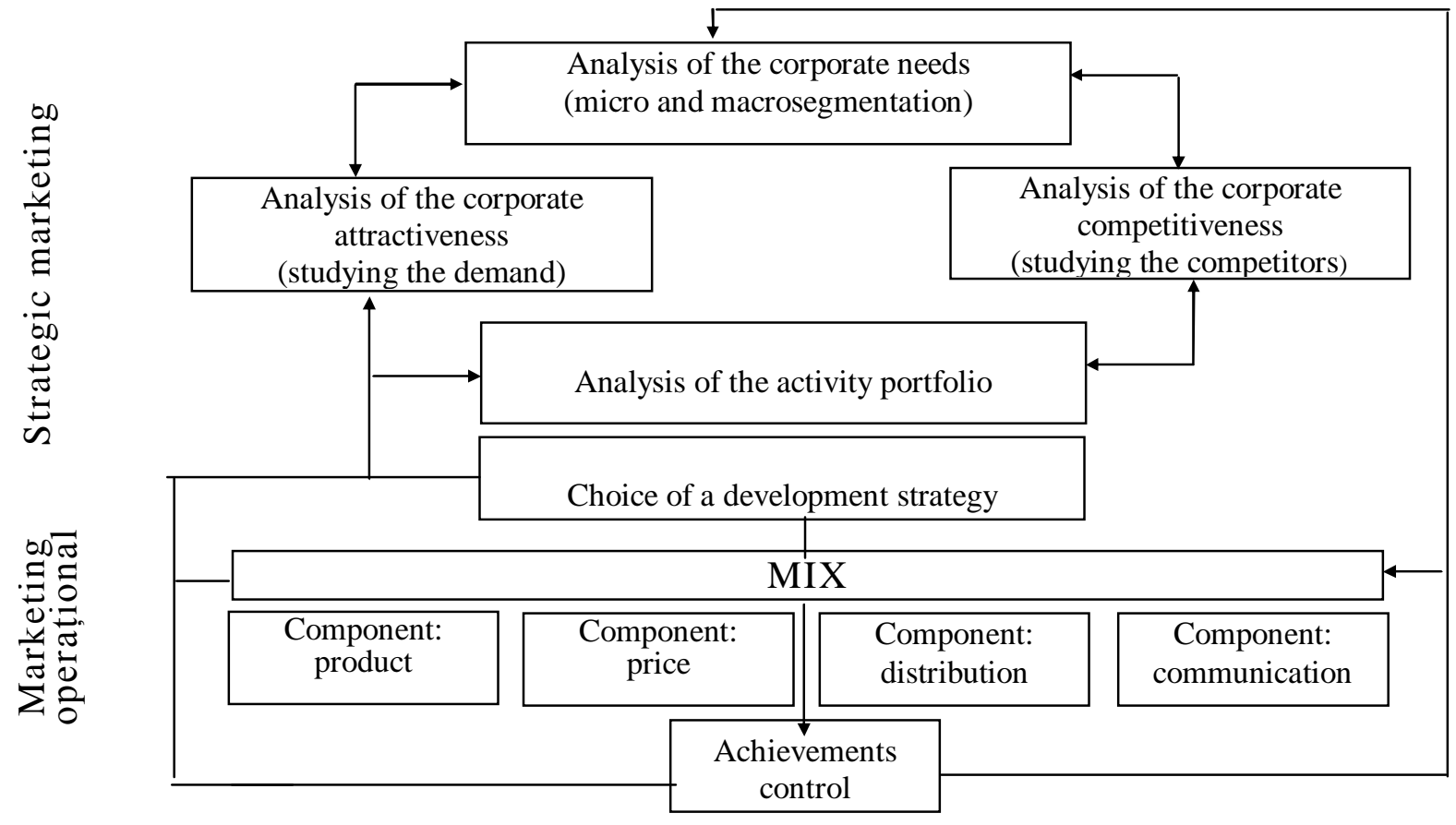

Figure no.1.- Complementariness of strategic marketing and operational marketing Source: P. Amerein and collaborators, 2002, p.6.

\section{The methodological framework of our research}

In the context of the methodology set for the elaboration of the present paper, we included the realization of a marketing research, aiming to determine the place occupied by strategic marketing in the SMEs' preoccupations in Dâmbovița County, but also an analysis of the way in which the SMEs, on the one hand, and the large companies, on the other hand, use strategic marketing opportunities in order to adapt themselves to the new realities brought about by globalization and by the market dynamics in the context of the international economic crisis.

The main purpose of our research was to find out the strategic marketing implementation level in the SMEs from Dâmbovița County.

The goals of the research that we have carried out were:

- to find out the place occupied by strategic marketing in the preoccupations of the SMEs in Dambovita County;

- to identify the extent to which the SMEs in Dâmbovița County hold enough knowledge concerning the analysis methods regarding the market or their internal or external environment;

- to bring to light the tendency of the SMEs in Dămbovița County to establish well elaborated competitive strategies.

The hypotheses of our research are:

I1: Strategic marketing remains a feature of large companies and not of SMEs.

I2: SMEs do not carry out studies in order to find out the extent to which they have satisfied their clients.

I3: SMEs do not hold enough knowledge concerning the analysis methods regarding the market or the internal or external environment and usually do not elaborate any competitive strategy.

The collectivity analyzed. The general collectivity is represented by the totality of the enterprises in Dâmbovița County. The observation unit is represented by: the enterprise in 
Dâmbovița County, and the survey unit is the general manager or the director of the marketing department.

Information gathering method. We have opted for the processing of the information based on a questionnaire containing preset questions. The survey technique used was the face to face survey.

Information gathering tool. We have used a questionnaire made up of 24 questions, of which 16 closed-ended, 2 open and 6 mixed.

The size of the sample. The research was carried out on a representative sample of 124 enterprises.

Sampling scheme. We have used a simple random sampling scheme. As an operational variant for the implementation of the simple random sampling, we have used a list of the enterprises from Dâmboviţa County; according to the existing number from each activity domain, we have chosen a certain percentage for the sample to be representative, dimensionally fit both for the sphere of the SMEs and for that of the large companies.

Data gathering period. The information was gathered in April 2008, the interview operators being masteral students from the Faculty of Economics of Valahia University Târgovişte.

As far as the scalar methods used were concerned, we employed the semantic differential scale, more precisely the variant containing five steps.

\section{Research results}

Below, we will present our main conclusions drawn from the analysis of the information processed based on the completed questionnaires. Given the limited space of our presentation, we had to preserve only a part of the questions used in the questionnaire; we have retained only the questions that we have considered relevant to support the hypotheses of the research we had in view.

Question: Who are your main clients?

The sample was structured, according to the answers to this question, as follows:

a) According to the clients' nature:

- $42 \%$ enterprises or organizations (professional clients);

- $58 \%$ the general public (final clients).

b) According to the size of the enterprise:

- The largest share of the enterprises addressing especially the general public is held by enterprises with a number of employees between 1 and $10(75 \%)$;

- The clients that are part of the professional users category are most of them enterprises with a number of employees over 50 people $(50 \%)$.

c) According to the activity domain:

- The enterprises providing collective, social and personal services deal - in a proportion of $100 \%$ - directly with the final clients (the general public);

- The firms in the processing industry mainly address the general public (75\%);

- Out of the enterprises addressing mainly the large public, the highest share goes to the firms of the trading domain (retail and wholesale), car repair and household goods.

Question: What was your enterprise's market share on the Romanian market during the last year?

\% out of the total sample

$\begin{array}{lll}\text { - } & <3 \% & 67.23 \\ \text {. } & 3 \%-14.9 \% & 13.45 \\ \text { - } & 15 \%-30 \% & 10.92 \\ & >30 \% & 8.40\end{array}$


a) A market share under $\mathbf{3 \%}$ is held by $88.24 \%$ of the firms with a maximum of 10 employees, $66.15 \%$ of the firms with $10-50$ employees and just $35 \%$ of the enterprises with over 50 employees. Within the limits of this small market share one can find: $100 \%$ of the educational institutions, $87.5 \%$ of the electricity/water/gas enterprises, and also $75 \%$ of the firms providing collective, social and personal services.

b) A market share over $\mathbf{3 0 \%}$ is held by a quarter of the enterprises with over 50 employees.

The highest share of the enterprises with a market share over $30 \%$ goes to the transport, storage and communication firms $(28.57 \%)$, as well as to some of the firms providing collective, social and personal services $(25 \%)$.

Question: How do you see the competition in the activity domain in which your firm operates?

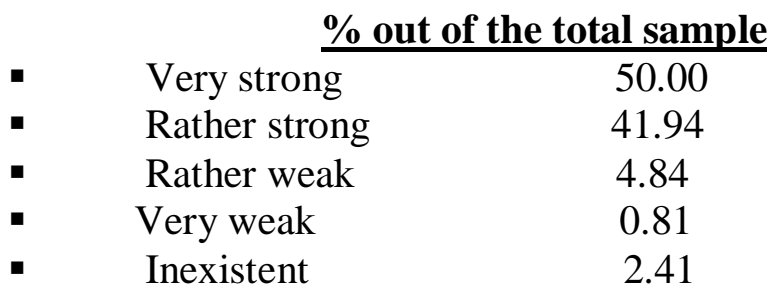

a) Out of the enterprises with 1-10 employees, $52.78 \%$ have appreciated that they are faced with a very strong competition, while $2.78 \%$ have answered that they operate on a market without competition.

b) $46.97 \%$.of the enterprises with $10-50$ employees consider that they are facing a very significant competition.

c) Out of the firms with over 50 employees, $54.55 \%$ consider that they are facing a very strong competition.

d) Taking into account their activity domain, $100 \%$ of the educational institutions included in the sample deploy their activity on a market with a very significant competition.

e) At the opposite pole, $20 \%$ of the firms that carry out other activities of collective, social and personal services, as well as $10 \%$ of the firms from the market of real estate transactions, rental and other activities provided mainly to enterprises, have indicated a lack of competition on their market.

Question: How well do you know the activity of your direct and indirect competitors? Direct competitors

\begin{tabular}{|c|c|}
\hline & $\%$ out of the total sample \\
\hline - $\quad$ Very well & 25.00 \\
\hline - Well & 42.74 \\
\hline - Satisfactorily & 24.19 \\
\hline Poorly & 4.03 \\
\hline Not at all & 1.61 \\
\hline
\end{tabular}

Over two thirds of the enterprises that undertook the survey know the activity of their direct competitors well and very well.

The score gets near 4 , suggesting a good reputation of the direct competitors.

$>$ Indirect competitors

- Very well

- Well

- Satisfactorily

- Poorly

- Not at all
\% out of the total sample

38.71

35.48

13.71

3.23 
The resulting tendency is that usually the respondent enterprises know their indirect competitors well $(38.71 \%)$ or satisfactorily $(35.48 \%)$.

Question: What is the main information on its competitors' activities that your enterprise has in view?

The firms with 1-10 employees mainly look for information concerning the prices practiced by their competitors (32.94\% of the number of this sample) and - to a lower extent - concerning the consumer segments they target $(23.53 \%)$.

It can be noticed that the firms from Dâmbovița County do not have a clearly defined strategy for themselves and have not made the necessary researches to obtain precise information on the their competitors' activities. competitors?

Question: From what sources have you got the information on your enterprise's

The survey highlights the fact that only the firms with over 50 employees are preoccupied with the study of their competitors' products, on the basis of research works undertaken in this sense.

Question: Which of the following methods do you use to analyze the activity of your enterprises through the prism of marketing? (answer variants: studying the market based on market surveys; forecasting the sales; a product's lifecycle curve; the analysis of the activities portfolio; Ansoff's product market expansion grid; SWOT analysis)

a) Almost half of the firms with 1-10 employees, as well as a third of the firms with 10-50 employees have answered that they use only the sales forecasting method.

b) Out of the large firms, significant answer ratios have in view the study of the market based on market surveys (that is expectable for large firms), sales forecasting and SWOT analysis.

Question: What information on the clients do you consider useful for your firm's marketing activity?

As a general tendency, one can notice the preoccupation - especially of the firms with over 50 employees - to gather information on the number of actual and potential consumers (almost a third of them).

Question: Evaluate the importance of the following micro-environmental factors according to the influence they could have on your firm's activity.

Using the semantic differential score, we have calculated an average score between 1 ("of very little importance") and 5 ("very important). In a decreasing order, the highest scores were obtained for:

- clients: 4.88;

- providers: 4.30 ;

- competitors: 4.12 .

Question: Evaluate the importance of the following macro-environmental factors according to the influence they can have on your firm's activity.

The calculated average score ranks the environmental factors as follows:

- economic environment: 4.65, which is considered normal, taking into account its instability on the background of the existing tensions;

- technological environment: 3.77

- demographic environment: 3.69;

- legislative environment:3.61;

- cultural environment: 2.87 ;

- political environment: 2.57 ;

- natural environment: 2.67. 
.Question: Which of the following resources available to your firm do you consider more important for obtaining a competitive advantage?

a) The firms that undertook the survey considered that all the 5 types of resources provided as response variants are very important (material, financial, informational, technological, managerial).

b) However, the highest scores were obtained by the financial and managerial resources, which indeed have a determining role in obtaining a competitive advantage.

Question: To what extent do you consider that the following elements differentiate your firm's activity from that of its competitors? (crucial success factors: product portfolio, quality-price report, sales methods, distribution networks, advertising, clients/providers relations)

a) The fact that the firms that undertook the survey have chosen more than one answer to this question demonstrates once again the lack of a strategy, having in view that the specialized theory supports the promotion of 1-2 crucial factors that confer a competitive advantage in order to obtain success on the market.

b) The highest score has been obtained by the quality/price report (4.6), and the lowest one by advertising (3.36), highlighting the lack of preoccupation for the communication with the clients. strategy?

Question: At present, does your company have an expressedly formulated marketing

a) Only the enterprises with over 50 employees have mentioned - in an overwhelming proportion (78.95\%) - the existence of a marketing strategy.

b) As far as their activity domain is concerned, the firms with high proportions of affirmative answers are those in education and real estate transactions, rentals and other activities provided mainly to enterprises.

c) At the opposite pole, namely firms without a marketing strategy, we could mention the firms operating in domains such as: transport, storage and communications, but also other activities of collective, social and personal services.

Question: Who makes the decisions concerning the marketing strategy in your enterprise?

a) The highest answer ratio has focused on the answer variant: "the corporate leadership", as responsible for making marketing strategy decisions.

b) Significant ratios go to the firms that have answered that their marketing-strategy-related decisions are made by the specialized personnel in the marketing department, namely $40 \%$ of the transport, storage and communications firms and $61.54 \%$ of the electricity, thermal energy, and gas and water enterprises.

Question: What market strategy has your company adopted in relation to its present competitive position on the market?

a) Out of the whole sample, $85.33 \%$ of the firms consider that they have an offensive strategy, aiming to improve their market position through the increase of their market share.

b) $100 \%$ of the companies from the extractive and processing industry; from the electrical and optical equipments industry; transport, storage and communications; education; other activities from the domain of collective, social and personal services consider that they have an offensive strategy aiming to improve their market position through the increase of their market share.

Question: What is the market strategy adopted by your enterprise in relation to the structure of the market?

a) In the entire sample, most enterprises $(54.05 \%)$ approach a differentiated strategy, which corresponds to a normal tendency in point of marketing evolution.

b) $100 \%$ of the enterprises operating in domains such as transport, storage and communications; education; other activities of collective, social and personal services consider that they have a differentiated strategy, elaborating a marketing mix for each market segment. 
c) Only $25 \%$ of the firms from the extractive and processing industry and that of real estate transactions, rentals and other activities provided mainly to enterprises have adopted a focused strategy, developing a specific marketing mix for just one market segment.

\section{Conclusions}

The most significant message of our research out in the field is that the initial hypotheses have been confirmed, so we can keep in mind that: Strategic marketing remains the characteristic instrument of large companies, and not of SMEs; SMEs do not carry out studies in order to know their clients' satisfaction level.; At the same time, they do not hold enough knowledge concerning the methods that could be used to analyze the market or the internal or external environment and have not gone into the details of the elaboration of any competitive strategy.

In an attempt to synthesize the results of the survey carried out, we appreciate that the general image on the enterprise sample chosen is that they are companies with an inconsistent marketing, namely with a marketing activity characterized, mainly, by: a focus on the price, reaction only to the competitors' actions, orientation towards the mass market, especially towards the increase of the market share, impetus created by the product.

Starting from these shortcomings present so far in the marketing activity of the companies with their headquarters in Dambovita County, we consider that the introduction of a new leadership (governance) mentality for the enterprise in the medium and long run is crucially important for business success. Such a mentality should rely on a strategic marketing thinking, which, in its turn, should rely on the following main hypotheses: Marketing reunites the activities of analyzing, creating and providing value for the client and should have more influence on the rest of the organization; Marketing should focus on: 1) strategy for establishing the targets on the market (identifying the market segments); 2) determining the targets in different environments; 3) strategic positioning and what it involves, namely determining a positioning strategy for each market target and 4) evaluating the efficiency of this positioning. Marketing should focus on keeping one's clients and consolidating their fidelity.

\section{References}

1. Amerein P., Barczyk D., Evdrard R., Rohard F., Sibaud B., Weber P., 2002. Manual de marketing strategic şi operațională, Teora Publishing House, Bucharest.

2. Antoine J., 1995. La stratégie, vue par les hommes de marketing, Revue Francaise du Marketing, ADETEM, nr.155

3. Cravens W.D., Piercy F.N., 2009. Strategic Marketing. Nineth Edition, McGraw-Hill International Edition

4. Florescu C. (coord), Balaure V., Boboc Şt., Cătoiu I., Olteanu V., Pop N. Al., 1992. Marketing, Marketer Publishing House, Bucharest

5. Kotler Ph., 2004. Marketing de la A la Z, Codecs Publishing House, Bucharest

6. Kotler Ph., 1997. Managementul marketingului, Teora Publishing House, Bucharest

7. Lambin J.-J., 1999. Marketing strategique. Du marketing a l'orientation-marche. 4-e edition, Paris, Ediscience International

8. Lambin J.-J., 1994. Le Marketing stratégique. Une perspective européenne, $3^{\mathrm{e}}$ édition, Ediscience International, Paris

9. Manu F. A., Sriram V., 1996. Inovation marketing strategy, enviroment and performance, Journal of Bussines research, vol.35

10. McDonald M., 1998. Marketing strategic, Codecs Publishing House, Bucharest

11. Pop N. Al. (coord), Andronov E. D., Kouzmanova M., Lefter C., Schmengler H. J., 2000. Marketing strategic, Economică Publishing House, Bucharest

12. Ries Al., Trout J., 1997. Marketingul ca război, Brandbuilders Publishing House, Bucharest 